\title{
Polyphenolic Extracts of Red Grapes
}

\author{
TN Gvinianidze ${ }^{1}$, MS Karchava ${ }^{1}$ and RH Jabnidze ${ }^{2}$ \\ ${ }^{1}$ Akaki Tsereteli State University, Georgia \\ ${ }^{2}$ Shota Rustaveli State University, Georgia
}

Submission: January 30,2018; Published: May 21, 2018

"Corresponding author: TN Gvinianidze, Akaki Tsereteli State University, Kutaisi, Georgia59, Tamar Mepe Str., 4600, Kutaisi, Georgia, Tel: +995 593 188353, Email: temuri1951@mail.ru

\begin{abstract}
Wine industry annually loses nearly several thousand tons of grape pomade as a result of processing tons of grapes. Pomade a magnificent raw material for the extraction of valuable products such as anthocyans (as medical food additives and food dyes), citric acid, ethanol, grape seed oil. The paper dwells on identification of phenolic compounds and anthocyanins from newly-squeezed grape skins and seed ethanol extracts of Zeibeli and Izabela color grape varieties cultivated in viticulture-winemaking micro-zone of western Georgia, by combined gas chromatography mass-spectrometry, and their determination by method of high-pressure liquid chromatography, but antioxidant activity has been assessed by DPPH method. For the experiment, we used newly-squeezed grape skins and seed without drying, mechanical and thermal treatment. Total phenolic compounds content in grape skins and seed ethanol extracts of Zeibeli variety ( $>423 \mathrm{mg} / 100 \mathrm{ml})$ was greater than in grape skins and seed extracts of Izabela variety $(>394,2 \mathrm{mg} / 100 \mathrm{ml})$. The same results have been registered when assessing antioxidant activity of extracts. In particular, in the conditions of the same dissolution of extracts, grape skins and seed ethanol extracts of Zeibeli variety had higher antioxidant activity (up to 67-79,4\%) than grape skins and seed extracts of Izabela variety $(49,5-63,9 \%)$. Studies have shown that total phenols and anthocyanins quantitative content correlates with antioxidant activity of extracts.
\end{abstract}

Keywords: Extracts; Grape-stone; Izabela; Zeibeli; Bio-flavonoids; Color; Experimental equipment

\section{Introduction}

Growth in radionuclide environmental background and chemicals use in food products are characterized by upset of antioxidant balance of human organism and pathologies of the immune system. Treatment and prevention of the mentioned pathologies and excretion of toxic substances from the body are possible only by using the drastic antioxidant, antitoxic and food born disease preventing plant preparations [1,2]. The best raw material base for producing such preparations and nutritional supplements is represented by environmentally safe, i.e. cultivated without using chemicals, colored grape varieties. Of particular interest is a grape stone, which contains 65$70 \%$ of total amount of phenol compounds existing in grapes, and is mostly represented by bio-flavonoids. They prevent the development of thromobotic proceses, improve lipid metabolism that in turn reduces pathologies of cardiac ischemic diseases and extends life expectancy [3]. Proanthocyanidins, which represent the catechins' polymeric chain were obtained for the first time by Professor Jacques Masquelier in 1936, and he named these compounds P vitamin.

Therapeutic-preventive daily norm of flavonoids for adults is $80-85 \mathrm{mg}$, but the upper acceptance limit in medicine is $120-130 \mathrm{mg} / \mathrm{per}$ day. They strengthen eliminating signals for cancer cells in human organism, so that they do not harm the healthy cells. In 2006, American scientists found proteins in the grapeseed ethanol extract, which foster the destruction of cancer cells [4].

It has been experimentally established that nutritional supplements containing total polyphenols of grape skins and stone are characterized by strong antioxidant synergism $[5,6]$ and they are activated even further in the presence of ascorbic acid. Thus, it is desirable to create such supplements from the compositions of therapeutic plant-based extracts concentrated by vacuum, and they will not be toxic even in the conditions of their long-term consumption. 


\section{Agricultural Research \& Technology: Open Access Journal}

Table 1: Show the quantitative content of phenolic compounds in the grape skins and stone ethanol extract of Zeibeli and Izabela varieties.

\begin{tabular}{|c|c|c|c|c|c|}
\hline \multirow{3}{*}{$\mathbf{N}$} & \multirow{3}{*}{ Name } & \multicolumn{4}{|c|}{ Concentration of phenolic compounds, $\mathrm{mg} / \mathrm{dm}^{3}$} \\
\hline & & \multirow[b]{2}{*}{ Total Quantity } & \multicolumn{2}{|c|}{ Monomeric Forms } & \multirow[b]{2}{*}{ Polymeric Forms } \\
\hline & & & Sum Total & $\begin{array}{c}\text { Including } \\
\text { Anthocyanins }\end{array}$ & \\
\hline 1 & $\begin{array}{c}\text { Grape skins and seed ethanol extract } \\
\text { of Zeibeli variety }\end{array}$ & 4230 & 1932 & 451 & 1847 \\
\hline 2 & $\begin{array}{c}\text { Grape skins and seed ethanol extract } \\
\text { of Izabela variety }\end{array}$ & 3942 & 1823 & 405 & 1714 \\
\hline
\end{tabular}

There are not studied in fact raw materials of colored chemical-free grape varieties (Izabela and Zeibeli) cultivated in the Imereti region's viticulture-winemaking micro-zone, each kilogram of which presumably contains about $10 \mathrm{~g}$ of phenolic compounds, and most of them (3\% of a dry mass) are concentrated in grape-stone $[7,8]$ (Table 1 ).

The content of anthocyanin in general parts of the grape reaches up to $450-2200 \mathrm{mg} / \mathrm{dm}^{3}$. The grape polyphenols represent drastic natural antioxidants and their biological activity in the presence of $\mathrm{C}$ vitamin it event grows further. They prevent free-radical destruction of bio-membrane cells structure, protect human organism in such pathological states, as atherosclerosis, stress, anemia, bronchitis, early ageing, intensive chemotherapy results, postoperative status, chronic fatigue syndrome and so on $[9,10]$.

Therefore, of high topicality is the development of innovative technologies of extracting dissoluble total polyphenols from raw materials of colored chemical-free grape varieties cultivated in the Imereti region's viticulture-winemaking micro-zone, for producing biologiclly active drastic antioxidant, antiradiant antiradiation, antitoxic and food born diseases preventing preparations.

Within the World Health Organization program MONICA and according to subsequent studies carried out in France, USA and other countries, it has been established that the therapeutic effect of red grape wine on human organism and its recommended daily norm is $70-100 \mathrm{ml}$, but not everybody can to intake this dose every day (children, patients, athlets, hardly working and religious people), consequently, the development of innovative technologies for producing from environmentally safe raw materials high antioxidant, antitoxic and foodborn diseases preventing polyphenol concentrate has a high pragmatic value $[11,12]$.

\section{Materials and Methods}

The selected raw materials for the study were Zeibeli and Izabela color grape varieties cultivated in Baghdati viticulturewinemaking micro-zone.

The process of cultivating the mentioned grape varieties does not involve the use of pesticides, chemicals and inorganic enriching agents.
To provide maximum extraction of the phenolic complex from newly-squeezed grape skins and stone, we arranged a series of experiments.

Extraction of grape secondary resources was carried out in two stages separately, independently of each other.

Based on the carried out studies and analysis of batchtype extraction equipment, we developed the innovative batchtype industrial and experimental extractor, which was used for performing experimental works, the principal scheme of which is shown below in Figure 1

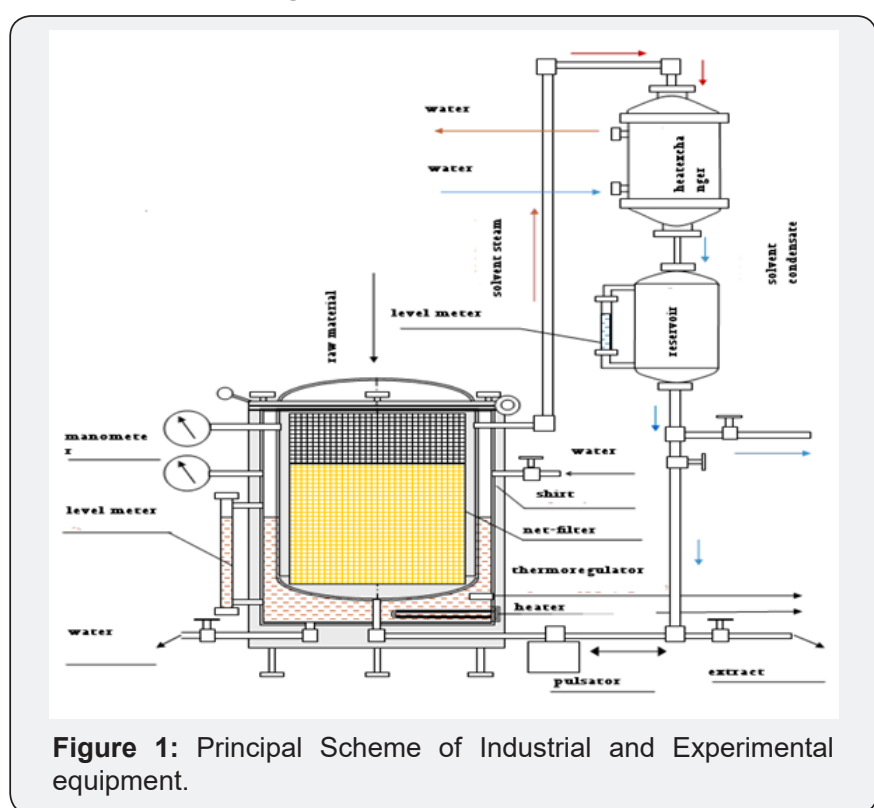

\section{At the first stage}

The newly-squeezed skins and stone, without any drying and crushing, are supplied to the extraction equipment, where per $1000 \mathrm{~g}$ of the grape skins and stone composition were added with $1000 \mathrm{ml}$ of $80-82 \%$ ethanol, which is oxidized to $1 \%$ by citric acid.

\section{At the second stage}

Per $1000 \mathrm{~g}$ of the extraction cake remaining in the extractor (i.e. skins and stone remaining after primary extraction) was added with $1000 \mathrm{ml}$ of $12-18 \%$ ethanol without oxidation, and extraction was carried out. At both stages, the extraction was carried out at the temperature of $45-50{ }^{\circ} \mathrm{C}$ within $4-4,5$ hours under conditions of periodical pulsation (Figure 2). 


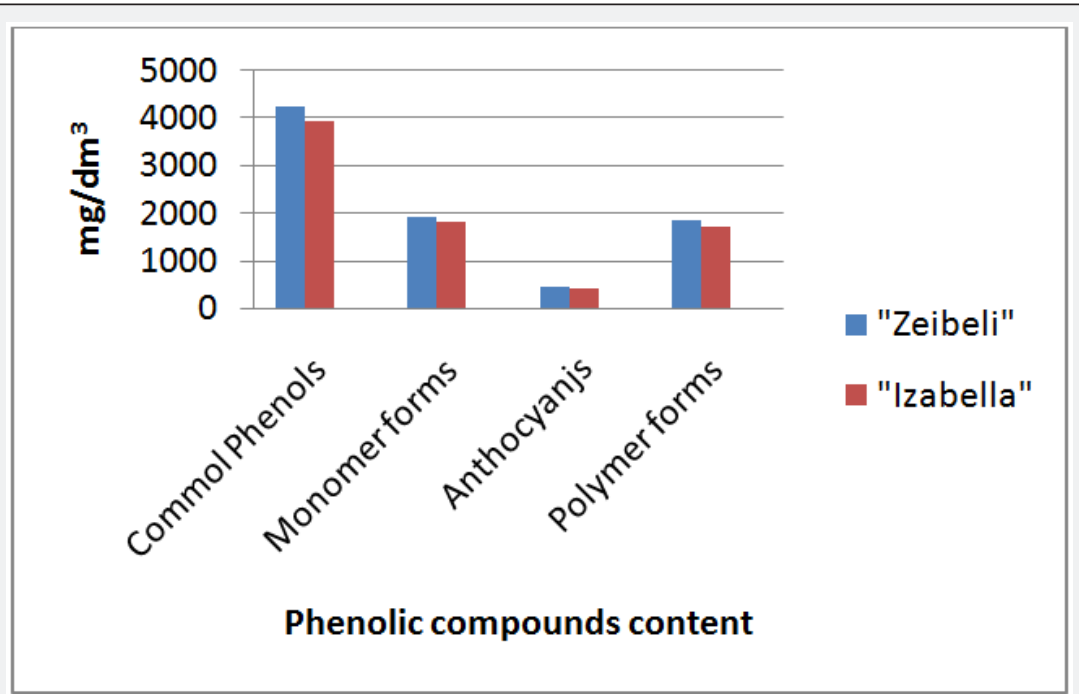

Figure 2: Phenolic compounds content in the extracts. Show the quantitative content of phenolic compounds in the grape skins and stone ethanol extract of Zeibeli and Izabela varieties.

The composition of extracts of both stages was centrifuged and filtered by means of German-made wine layered filters, and condensation-concentration of a part of the obtained extracts was carried out in a vacuum at the temperature of not higher than $50{ }^{\circ} \mathrm{C}$ until $57-63 \%$ of dry substances content.

For analysis, we used both uncondensed and condensed extracts for both grape raw materials separately.

Studies of physical-chemical characteristics of extracts were carried out in compliance with international standards (ISOInternational Organization for Standardization). In particular, as follows:

The content of water-soluble extracts: ISO 9768:1994, which envisages extraction in the conditions of reflux, filtration, drying of non-dissolved waste and weighing with further calculation of extracting substances;

Determination of phenolic compounds in the extracts was carried out by colorimetric (Folin-Ciocalteu) method, which is based on the capacity of phenolic compounds to recover phosphatotungstic and phosphatomolybdic acids,

And to measure the coloration intensity of a blue-color molybdenum to a rusting color by using colorimetric method.

$1 \mathrm{~cm}^{3}$ of extract, $15 \mathrm{~cm}^{3}$ of water, 1 Folin Ciocalteu reagent and $20 \mathrm{~cm}^{3}$ of $20 \%$ sodium carbonate solution were placed in the flask with a capacity of $100 \mathrm{~cm}^{3}$, and 30 minutes later we measured optical density by using the ditch with $10 \mathrm{~mm}$ thick and the wavelength of $670 \mathrm{~nm}$. For comparison, we prepared the second solution, in which $1 \mathrm{~cm}^{3}$ of sample of the analyzed extract was replaced by water.

The concentration of phenolic compounds was determined by a calibration curve of standard solution of Gallic acid [13,14].
To determine anthocyanins, we used the method of highpressure liquid chromatography by using the American-made chromatograph (Waters (UV/Visible Detector 2489, Binary HPLC Pump1525). The analyzed extract was filtered with a special-purpose chromatograph's filter $(0,45 \mu \mathrm{m})$, and we used chromatograph column Symmetry C18, 3,5 $\mu \mathrm{m} 4,6 \times 75 \mathrm{~mm}$, detection was carried out at 510 and $524 \mathrm{~nm}$, the solvent systems: $1 \%$ phosphorus acid (A), acetonitrile (B) and $5 \%$ formic acid (A), methanol (B) (Merk; Aldrich) in a linear gradient. Dissolution rate $-1 \mathrm{ml} / \mathrm{min}$, sample quantity - $20 \mu \mathrm{l}$. Duration of chromatography - 45 minutes $[15,16]$.

To determine antioxidant activity, i.e. radical binding activity, $1 \mathrm{ml}$ of the analyzed extract is added with $3 \mathrm{ml}$ of DPPH alcohol solution $(0,1 \mathrm{mM}$ DPPH - in $0,004 \mathrm{~g} / 100 \mathrm{ml}$ of ethyl alcohol), and 30 minutes later, there was carried out spectrophotometric determination of optical density of analyzed sample on $515 \mathrm{~nm}$. The reference solution is represented by DPPH solution, but the background - by $96 \%$ ethyl alcohol. During the research process, the optimal concentration of solution was determined for inactivation of DPPH radical for each standard compound [17-19].

\section{Results and Discussion}

An analysis of the research results has shown that many factors have a significant influence on the extraction process, including the ratio of extraction raw materials and extracting agent, extraction temperature, extracting agent polarity, degree of raw materials crushing, extraction method, pulsation frequency and so on.

Based on the analysis of available literature sources, it has been established that the extracts obtained from grape skins and stone without preliminary drying and crushing mostly possess health-promoting properties. Based on this, we selected for the 
extraction the newly-squeezed environmentally safe color grape skins and stone, and the extraction was carried out without drying and crushing.

The two-stage extraction at the temperature of $45-50{ }^{\circ} \mathrm{C}$ within 4-4,5 hours under pulsation conditions, is conditioned for increasing periodical pulsation and for maximal extraction of phenolic complex.

Enzyme preparations to optimize the extraction of juice from the grape mass, processing them and heated to $100{ }^{\circ} \mathrm{C}$, do not reduce the high content of phenols with AO-activity, making grape pomade important potential source of food additives.

The majority of red grape varieties, cultural and hybrid varieties of anthocyans is only a thin skin, very rare, but there are some varieties (eg. As red grapes "Dirbula" and "Zeimberi") which is also painted with the juice. The content of anthocyanin in general parts of the grape reaches up to $2200 \mathrm{mg} / \mathrm{dm}^{3}$.

The conducted research has shown a very high bio-flavanoid composition of eco-extracts, which in turn points to high antioxidant activity of extracts. The total phenols content is high enough in the grape skins and seed extracts of Zeibeli variety $(\geq 423 / 100 \mathrm{ml}$ ), and is relatively low in the similar extracts of Izabela $(\geq 394,2 / 100 \mathrm{ml})$.

Figure 3 Illustrates the chromatogram of the anthocyanins content in the grape skins and stone ethanol extracts of Zeibeli variety, where it is clearly seen that $63,04 \%$ of anthocyanins are represented by mono-glucosides, and the rest are the diglucosite and unknown forms.

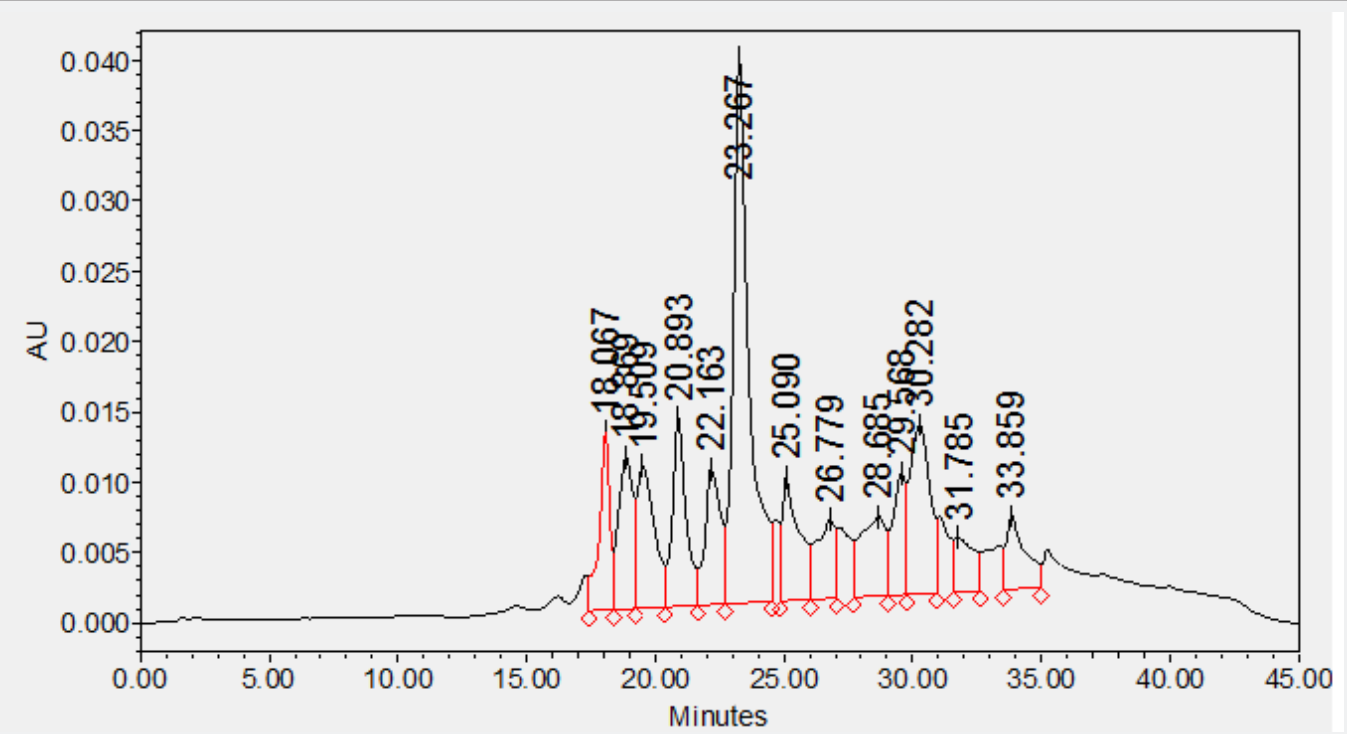

Figure 3: The chromatogram of the anthocyanins content in the grape skins and seed ethanol extracts of Zeibeli variety.

\begin{tabular}{|c|c|c|c|c|}
\hline & SampleName & Acq Method Set & Channel Description & ColumnType \\
\hline 2 & Extract-1 & Anthociane CH3CN 85 \% & W2489 ChB 524nm & C 18 \\
\hline
\end{tabular}

\begin{tabular}{|c|c|c|c|c|c|c|}
\hline & Name & Retention Time & Area & $\%$ Area & Height & Int Type \\
\hline 1 & $\begin{array}{l}\text { delphinidin-3- } \\
\text { monogalactoside }\end{array}$ & 15.389 & & & & Missing \\
\hline 2 & Peak2 & 16.048 & & & & Missing \\
\hline 3 & delpinidin-3-monoglucoside & 17.034 & & & & Missing \\
\hline 4 & Peak4 & 18.067 & 357189 & 5.61 & 12693 & $\mathrm{VV}$ \\
\hline 5 & cyanidin-3-monogalactoside & 18.869 & 430186 & 6.75 & 10831 & VV \\
\hline 6 & $\begin{array}{l}\text { delphinidin-3- } \\
\text { monoarabinoside }\end{array}$ & 19.509 & 474603 & 7.45 & 10125 & $\mathrm{VV}$ \\
\hline 7 & Peak7 & 20.893 & 501864 & 7.88 & 13422 & $\mathrm{VV}$ \\
\hline 8 & cyanidin-3-monoglucoside & 22.163 & 402541 & 6.32 & 9676 & $\mathrm{VV}$ \\
\hline 9 & malvidin-3-monoarabinoside & 23.267 & 1692237 & 26.57 & 38710 & $\mathrm{VV}$ \\
\hline 10 & petynidin-3-monoglucoside & 25.09 & 398121 & 6.25 & 8830 & $\mathrm{VV}$ \\
\hline 11 & peonidin-3-monogalactoside & 25.37 & & & & Missing \\
\hline
\end{tabular}


Agricultural Research \& Technology: Open Access Journal

\begin{tabular}{|c|c|c|c|c|c|c|}
\hline 12 & petunidin-3-monoarabinoside & 26.779 & 294660 & 4.63 & 5625 & VV \\
\hline 13 & petynidin-3-monogalactoside & 28.685 & 389792 & 6.12 & 5644 & VV \\
\hline 14 & peonidin-3-monoglucoside & 29.568 & 297645 & 4.67 & 8682 & VV \\
\hline 15 & & 30.282 & 650573 & 10.21 & 12074 & VV \\
\hline 16 & peonidin-3-monoarabinoside & 31.785 & 209002 & 3.28 & 3884 & VV \\
\hline 17 & & 33.859 & 271669 & 4.26 & 5199 & VV \\
\hline 18 & Peak16 & 38.941 & & & & Missing \\
\hline
\end{tabular}

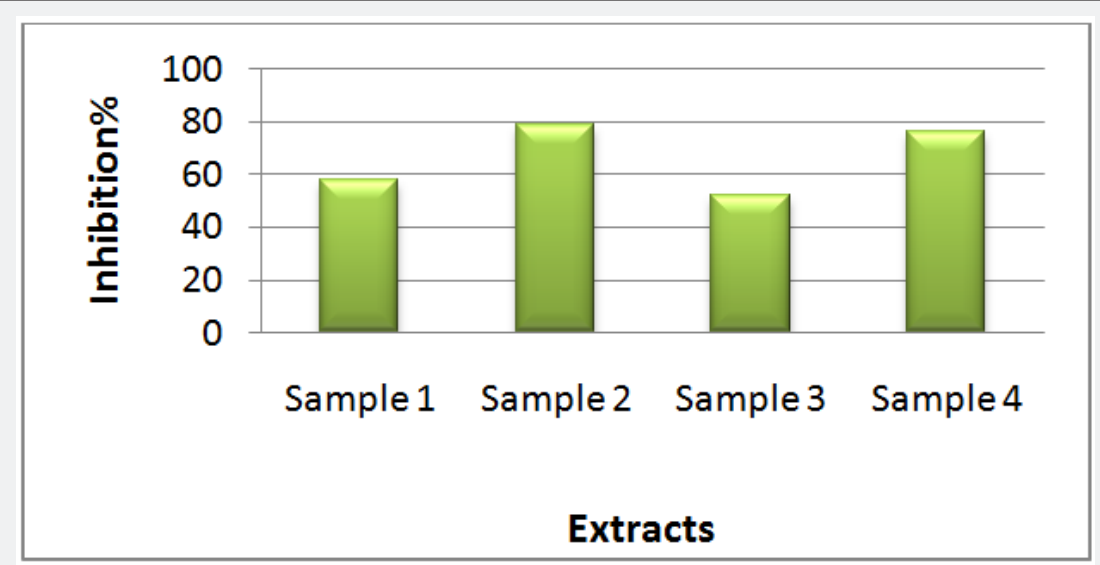

Figure 4: Binding of DPPH radical by the grape skins and seed extracts of Zeibeli (Sample1 and 2) Izabela (Sample 3 and 4) varieties.

Both types of extracts are characterized by high values of antioxidant activity (Figure 4).

The first and second samples illustrated in Figure 4 are the grape skins and seed extracts of Zeibeli variety, non-concentrated and concentrated, accordingly, but the third and fourth samples are the grape skins and seed extracts of Izabela variety, nonconcentrated and concentrated, accordingly.

Antioxidant activity of both non-concentrated and concentrated eco-extracts is very high, and therefore, of high relevance is the use of hydrophilic and lipophilic extracts of secondary resources of Zeibeli and Izabela varieties in production of food supplements fortified with biologically active compounds.

The average annual polyphenol reserves of the grape harvest in Georgia, which is mostly accumulated in a practically unused grape-seed, exceeds several hundreds of tons that in monetary terms makes up millions of US dollars. Because of fact that such natural wealth is not used, the health losses in the population are considerable and obvious, although it is difficult to assess them properly. In addition, we propose environmentally safe raw materials of colored chemical-free grape varieties cultivated in the region, which are practically unused, and the local population seriously sensible about that, since one of the main fields of their activities in viticulture

\section{Conclusion}

By using the method of high-pressure liquid chromatography, in the color grape skins and seed extracts cultivated without use of chemical pesticides, there have been established a high content of total phenols and anthocyanins and antioxidant activity.
These resources are the best, ecologically pure raw materials for production of the drastic antioxidant polyphenolic concentrates.

\section{Author's Contribution}

T.N.Gvinianidze, M.S. Karchava and P.H. Jabnidze made equal contribution to this paper.

\section{Acknowledgments}

This work was supported by Shota Rustaveli National Science Foundation (SRNSF) [N216752, Developing Innovative Technologies of Drastic Antioxidant Polyphenol Concentrates].

\section{References}

1. Gvinianidze TN, Mamrikishvili L, Gvinianidze TT, Jabnidze RH, Mindeli VA, et al. (2014) Study of phenolic compounds Georgian variety grapestone and developing technology of food additive with radioprotective activity. Proceedings of International Scientific Conference, Climate Change and its Impact on Sustainable and Safe Development of Rural Economy. Academy of Agricultural Sciences of Georgia, pp. 257-260.

2. Revilla E, Ryan JM (2000) Analysis of several phenolic compounds with potential antioxidant properties in grape extracts and wines by high-performance liquid chromatography-photodiode array detection without sample preparation. J Chromatogr A 881(1-2): 461-469.

3. Polyphenolics, Inc. Technical Publication I.

4. Jang M, Cai L, Udeani GO, Slowing KV, Thomas CF, et al. (1997). Cancer chemopreventive activity of resveratrol, a natural product derived from grapes. Science 275(5297): 218-220.

5. Kennedy JA, Matthews MA, Waterhouse AL (2002) Effect of Maturity and Vine Water Status on Grape Skin and Wine Flavonoids. Am J Enol Vitic 53(4): 268-274.

6. Fulcrand H, Duenas M, Salas E, Cheynier V (2006) Phenolic Reactions during Winemakingg And Aging. Am J Enol Vitic 57(3): 289-297. 
7. Kanner J, Frankel E, Granit R, German B, Kinsella JE (1994) Natural antioxidants in grapes and wines. J Agric Food Chem 42(1): 64-69.

8. (1986) Viticulture encyclopedia, Vol.3./Editorial board -- A.S Subbotovich, Kishinev. Edition of Moldavian Soviet Encyclopedia, Russia.

9. Keli SO, Hertog MG, Feskens EJ, Kromhout D (1996) Dietary flavonoids, antioxidant vitamins, and incidence of stroke: the Zutphen study. Arch Intern Med 156(6): 637-642.

10. Filipe P, Lança V, Silva JN, Morlière P, Santus R, et al. (2001) Flavonoids and urate antioxidant interplay in plasma oxidative stress. Molecular and Cellular Biochemistry 221(1-2): 79-87.

11. Gabidzashvili MA, Gvinianidze TT, ChokhonelidzeVA (2014) The results of studying hydrophilic compounds of Saperavi variety grapestone. Proceedings of I International Scientific-Practical Conference. Stavropol: 91-93.

12. Burns J, Gardner PT, O’Neil J, Crawford S, Morecroft I, et al. (2000) Relationship among antioxidant activity, vasodilation capacity, and phenolic content of red wines. J Agric Food Chem 48(2): 220-230.

13. Gerzhikova VG (2009) Methods of techno-chemical control in wine production. Simferopol (in Russian).
14. Japaridze I, Kamadadze E (2010) The Maintenance of Phenol Compounds In Fruits Of Cherry-Laurel of Variety Sorts. Works of international scientific-practical conference "Innovative Technologies and Contemporary Materials” Kutaisi, Georgia, pp. 399-400.

15. Vanidze M, Kalandia A (2010) Hplc Research Of Flavonols The Local Vegetative Raw Materials. Works of international scientific-practical conference. Innovative Technologies and Contemporary Materials Kutaisi: 394-395.

16. Vanidze M, Japaridze I, Kalandia A, Kamadadze E (2010) HPLC research of anthocyans the local vegetative raw materials. Works of international scientific-practical conference innovative technologies and contemporary materials Kutaisi: 395-396.

17. Singleton VL, Orthofer R, Lamuela-Raventós RM (1999) Analysis of total phenols and other oxidation substrates and antioxidants by means of folin-ciocalteu reagent. Methods in Enzymology 299: 152-178.

18. Mulero J, Pardo F, Zafrilla P (2010) Antioxidant activity and phenolic composition of organic and conventional grapes and wines. Journal of Food Composition and Analysis 23(6): 569-574.

19. Okawa M, Kinjo J, Nohara T, Ono M (2001) DPPH (1,1-Diphenyl-2Pierylhydrazyl) Radical Scavenging activity of Vlavonoids Obtained from Some Medical Plants. Biol Pharm Bull 24(10): 1202-1205.

Your next submission with Juniper Publishers will reach you the below assets

This work is licensed under Creative

Commons Attribution 4.0 License

DOI: 10.19080/ARTOAJ.2018.16.555981 